\title{
Covid-19: diabetes clinicians set up social media account to help alleviate patients' fears
}

\author{
Gareth lacobucci
}

The BMJ

A group of diabetes doctors and other clinicians has set up a social media account to help alleviate patients' fears around covid-19 and provide them with "a secure base" of information.

Around one in 13 people in the UK has diabetes, roughly $90 \%$ type 2 diabetes and $10 \%$ type 1 . The UK government has advised that all people with diabetes-along with other at-risk groups-should be "particularly stringent" in following social distancing measures that ministers have set out for the whole country to follow.

But after hearing concerns and confusion from people with diabetes, their families, and their carers about what measures they need to take, a group of clinicians including consultant diabetologists, GPs, specialist nurses, psychologists, and pharmacists decided to set up a Twitter account Diabetes 101 ${ }^{1} @$ _diabetes 101 to provide trusted advice.

Partha Kar, consultant in diabetes and endocrinology in Portsmouth and NHS England's national specialty adviser on diabetes, has been among those involved in setting up the account, which launched on Monday 23 March.

He told The BMJ that the clinicians wanted to provide "a credible source of guidance during what has fast become an epidemic of misinformation."

"After seeing the distress and anxiety people living with diabetes were experiencing when news of the covid-19 outbreak hit, along with the desire for accurate information, a group of diabetes healthcare professionals have decided to get together to try and help as much as possible," he said.

"We wanted to alleviate fears around covid-19 as well as provide people with a secure base to gain reassurance from."

The account is operated by two or three healthcare professionals a day to answer people's queries. It has been reaching about 170 000 impressions a day and has provided direct advice to hundreds of people since it launched.

As well as providing advice, the account is facilitating activities and discussions designed to help reduce people's anxieties and promote psychological resilience.

Kar added: "The aim is to provide people with trusted and verified advice, as well as regular daily activities to help provide a daily structure, promote positive health behaviours, and boost morale during the coronavirus pandemic. By routinely answering questions, the account may play a role in reducing some of the increased burden that diabetes teams and GP surgeries are currently holding."

\footnotetext{
Twitter. https://twitter.com/_diabetes101.
}

Published by the BMJ Publishing Group Limited. For permission to use (where not already granted under a licence) please go to http://group.bmj.com/group/rights-licensing/ permissions 